\title{
Thyroid function in obese Korean children and adolescents: Korea National Health and Nutrition Examination Survey 2013-2015
}

\author{
Young Min An, MD', \\ Soon Jeong Moon, $\mathrm{MD}^{1}$, \\ Soon Ki Kim, MD, PhD', \\ Young Ju Suh, PhD', \\ Ji Eun Lee, MD, PhD ${ }^{1}$
}

'Department of Pediatrics, Inha University School of Medicine, Incheon; ${ }^{2}$ Department of Biomedical Sciences, Inha University School of Medicine, Incheon, Korea
Received: 10 October, 2017

Revised: 10 November, 2017

Accepted: 17 November, 2017

Address for correspondence:

Ji Eun Lee, MD, PhD

Department of Pediatrics, Inha University Hospital, Inha University School of Medicine, 27 Inhang-ro, Jung-gu, Incheon 22332, Korea

Tel: $+82-32-890-3617$

Fax: +82-32-890-3099

E-mail: anicca@inha.ac.kr

https://orcid.org/0000-0002-7386-

0015
Purpose: In recent years, there has been an increasing focus on thyroid function in pediatric obese patients, but no nationwide study evaluating the relationship between thyroid function and obesity has yet been conducted in Korea. We aimed to evaluate thyroid dysfunction in obese Korean children.

Methods: We analyzed the associations between obesity and thyroid hormone levels among 975 Korean boys and girls aged 10-18 years and who participated in the Korean National Health and Nutrition Examination Survey VI (2013-2015).

Results: Average serum thyrotropin (TSH) and serum free thyroxine (fT4) levels in the nonobese group were $2.7 \pm 0.1 \mu \mathrm{IU} / \mathrm{mL}$ and $1.3 \pm 0.0 \mathrm{ng} / \mathrm{dL}$, respectively, and those in the overweight group were $3.1 \pm 0.2 \mu \mathrm{IU} / \mathrm{mL}$ and $1.2 \pm 0.0 \mathrm{ng} / \mathrm{dL}$. Serum TSH level was significantly higher in the abdominal obesity group than in the normal group $(P=0.023)$. fT4 level was significantly lower in both the overweight and abdominal obesity groups than in the normal group $(P<0.001, P=0.014)$. Serum TSH level was associated positively with abdominal obesity and levels of high-density lipoprotein cholesterol and triglyceride. Serum fT4 level was negatively correlated with abdominal obesity $(P=0.014)$.

Conclusion: Korean children with abdominal obesity showed increased TSH and decreased fT4 levels compared to normal children.

Keywords: Obesity, Abdominal obesity, Thyroid hormone, Child

\section{Introduction}

Obesity is a worldwide health problem, and its global prevalence has increased dramatically over the past three decades. Obese children are far more likely than normal weight children to develop dyslipidemia, elevated blood pressure, and insulin resistance, which significantly increase their risk of cardiovascular and metabolic diseases. ${ }^{1)}$ Several hormonal changes are reported in obesity. Some of these changes are considered secondary effects of obesity and are usually restored after weight loss. ${ }^{2-8)}$ In recent years, there has been increasing attention on thyroid function in patients with obesity. Several studies have reported moderately elevated thyrotropin (TSH) and normal or slightly elevated free triiodothyronine (fT3) levels in obese subjects. ${ }^{3-8)}$ Positive correlations were found between actual serum TSH levels and weight gain. ${ }^{8)}$ The mechanisms leading to increased TSH and fT3 levels in patients with obesity are still unclear.

No nationwide study evaluating the relationship between thyroid function and obesity in children has yet been conducted in Korea. We aimed to evaluate the association between thyroid function and obesity in Korean children using data obtained from the Korean National Health and Nutrition Examination Survey (KNHANES) conducted from 2013 to 2015. 


\section{Materials and methods}

\section{Subjects}

We used data from the KNHANES VI (2013-2015). The target population of KNHANES comprises noninstitutionalized Korean citizens residing in Korea. The sampling plan follows a multistage-clustered probability design. ${ }^{9)}$ This cross-sectional and nationally representative survey was conducted by the Korea Centers for Disease Control and Prevention (KCDC).

Blood samples were collected from children aged $\geq 10$ years. From 2013 to 2015, a survey was conducted annually that included 2,425 children and adolescents aged 10-18 years. We excluded individuals for whom data on TSH levels were missing $(n=1,404)$, as well as patients who had not fasted for at least 8 hours prior to blood sampling $(n=19)$. Twenty-seven adolescents who had increased levels of thyroid peroxidase autoantibodies (TPO Ab>34.0 IU/mL) were also excluded. Ultimately, the study population consisted of 975 children and adolescents ( 516 boys and 459 girls). The KNHANES has been reviewed and approved by the KCDC annually (2013-07CON-
03-4C, 2013-12EXP-03-5C, 2015-01-02-6C). This study was approved by the Institutional Review Board of Inha University Hospital (INHAUH 2017-10-017).

\section{Anthropometric and biochemical measurements}

Waist circumference (WC) was measured to the nearest 0.1 $\mathrm{cm}$ at the midpoint between the bottom of the rib cage and the top of the iliac crest, with the subject standing. Systolic blood pressure (SBP) and diastolic blood pressure (DBP) were measured three times while the subjects were seated, and the two last measurements were averaged for the analysis.

Blood samples were obtained after an 8-hour overnight fast for analysis of lipid profile, namely, triglycerides (TG), total cholesterol, and high-density lipoprotein (HDL) cholesterol. $\mathrm{TSH}, \mathrm{fT} 3$, and free thyroxine (fT4) levels were measured by electrochemiluminescence immunoassays (Roche Diagnostics, Mannheim, Germany). The normal values range between 0.35 and $5.50 \mathrm{mIU} / \mathrm{L}$ for TSH, and between 0.89 and $1.76 \mathrm{ng} / \mathrm{mL}$ for fT4.

Table 1. Characteristics of the study subjects who 10-18 years old children and underwent thyroid function tests as part of the Korea National Health and Nutrition Examination Survey IV (2013-2015)

\begin{tabular}{|c|c|c|c|}
\hline \multirow{2}{*}{ Characteristic } & \multicolumn{3}{|c|}{ Status of obesity* } \\
\hline & Total & Nonobese & Overweight \\
\hline No. of patients (\%) & 975 & $757(77.7)$ & $218(22.4)$ \\
\hline \multicolumn{4}{|l|}{ Demographics } \\
\hline Age (yr) & $14.3 \pm 0.1$ & $14.2 \pm 0.1$ & $14.3 \pm 0.2$ \\
\hline Female sex & $459(46.8)$ & $355(46.3)$ & $104(48.2)$ \\
\hline \multicolumn{4}{|l|}{ Anthropometric indexes } \\
\hline$W C(\mathrm{~cm})$ & $71.2 \pm 0.4$ & $67.7 \pm 0.3$ & $83.5 \pm 0.7$ \\
\hline $\mathrm{BMI}\left(\mathrm{kg} / \mathrm{m}^{2}\right)$ & $21.4 \pm 0.1$ & $19.8 \pm 0.1$ & $26.7 \pm 0.3$ \\
\hline BMI z-scores & $-0.1 \pm 0.1$ & $-0.2 \pm 0.0$ & $1.7 \pm 0.0$ \\
\hline \multicolumn{4}{|l|}{ Blood pressure } \\
\hline Systolic (mmHg) & $108.9 \pm 0.4$ & $107.4 \pm 0.4$ & $113.8 \pm 0.7$ \\
\hline Diastolic (mmHg) & $66.2 \pm 0.3$ & $65.9 \pm 0.4$ & $67.2 \pm 0.6$ \\
\hline \multicolumn{4}{|l|}{ Biochemical indexes } \\
\hline Fasting glucose (mg/dL) & $91.8 \pm 0.4$ & $91.6 \pm 0.4$ & $92.4 \pm 0.5$ \\
\hline $\mathrm{HbA}_{1 c}(\%)$ & $5.5 \pm 0.0$ & $5.4 \pm 0.0$ & $5.5 \pm 0.0$ \\
\hline Total serum cholesterol (mg/dL) & $158.6 \pm 1.0$ & $157.2 \pm 1.1$ & $163.5 \pm 2.1$ \\
\hline HDL cholesterol (mg/dL) & $51.9 \pm 0.4$ & $53.0 \pm 0.4$ & $48.3 \pm 0.8$ \\
\hline $\mathrm{TG}(\mathrm{mg} / \mathrm{dL})$ & $82.8 \pm 1.9$ & $78.4 \pm 1.7$ & $98.0 \pm 5.1$ \\
\hline \multicolumn{4}{|l|}{ Thyroid related traits } \\
\hline $\mathrm{TSH}(\mu \mathrm{IU} / \mathrm{mL})$ & $2.8 \pm 0.1$ & $2.7 \pm 0.1$ & $3.1 \pm 0.2$ \\
\hline fT4 (ng/dL) & $1.3 \pm 0.0$ & $1.3 \pm 0.0$ & $1.2 \pm 0.0$ \\
\hline Abdominal obesity $^{\dagger}$ & $113(12.3)$ & $6(0.8)$ & 107 (49.1) \\
\hline High TSH $(>5.5 \mu \mathrm{lU} / \mathrm{mL})$ & $62(6.4)$ & $44(5.8)$ & $18(8.3)$ \\
\hline
\end{tabular}

Values are presented as mean \pm standard deviation or number (\%).

WC, waist circumference; BMI, body mass index; $\mathrm{HbA}_{1 \mathrm{c}}$ glycated hemoglobin; $\mathrm{HDL}$ cholesterol, high-density lipoprotein cholesterol; $\mathrm{TG}$, triglyceride; $\mathrm{TSH}$, thyroid stimulating hormone; fT4, free thyroxine.

Calculated by complex samples descriptives.

*Using 2007 Korean national growth chart, overweight defined BMI $\geq 85$ th percentile, nonobese group BMl<85th percentile. ${ }^{\dagger}$ Abdominal obesity was defined as waist circumference (WC) $\geq 90$ th percentile for age and gender based on 2007 Korean national growth chart for children aged 10-16 years, and $\geq 90 \mathrm{~cm}$ for men and $\geq 80 \mathrm{~cm}$ for women as the ethnic-specific values for adolescents aged $\geq 16$ years. 


\section{Definition}

Obesity and overweight were defined according to the body mass index $(\mathrm{BMI}) \geq 85$ th percentile and $\geq 95$ th percentile, respectively. ${ }^{10)}$ Obesity degree was evaluated using the BMI $z$-scores, calculated with the LMS method. ${ }^{11)}$ We categorized the subjects with $\mathrm{BMI} \geq 85$ th percentile into the overweight and the remaining subjects into the nonobese group, and the cut-off value was based on the 2007 Korean National Growth Charts. ${ }^{12)}$

A determination of abdominal obesity in adolescents was based on the metabolic syndrome definition of the International Diabetes Federation. ${ }^{13)}$ Abdominal obesity was defined as WC $\geq 90$ th percentile for age and gender based on 2007 Korea Growth Charts for children aged $10-16$ years, and $\geq 90 \mathrm{~cm}$ for men and $\geq 80 \mathrm{~cm}$ for women as the ethnic-specific values for adolescents aged $\geq 16$ years. ${ }^{12,14)}$

\section{Statistical analysis}

Data were analyzed with the IBM SPSS ver. 18.0 (IBM Co., Armonk, NY, USA). The Complex Samples Plan, which is available as the complex samples option in later SPSS versions, was used for all analyses to account for sample weighting. All values were presented as means \pm standard deviation. A $P$-value of $<0.05$ was considered significant. The association between thyroid function and obesity was identified using simple and multiple linear regression analyses for the complex survey.

\section{Results}

\section{Baseline characteristics of the study population}

The anthropometric and laboratory characteristics of the study participants are shown in Table 1. Among the subjects, $22.4 \%$ were in the overweight. The average age and the proportion of sex (female) were $14.3 \pm 0.2$ years and $48.2 \%$ in the overweight and $14.2 \pm 0.1$ years and $46.3 \%$ in the nonobese group, respectively. The average WC and BMI $z$-scores values were $83.5 \pm 0.7 \mathrm{~cm}$, and $1.7 \pm 0.0$ in the overweight and $67.7 \pm 0.3$ $\mathrm{cm}$, and $-0.2 \pm 0.0$ in the nonobese group, respectively. SBP was higher in the overweight $(113.8 \pm 0.7 \mathrm{mmHg})$ than that in the nonobese group $(107.4 \pm 0.4 \mathrm{mmHg})$, but DBP values in these groups were similar in both groups $(67.2 \pm 0.6 \mathrm{mmHg}$ and $65.9 \pm 0.4 \mathrm{mmHg}$ ).

Average TG levels were seemed higher in the overweight $(98.0 \pm 5.1 \mathrm{mg} / \mathrm{dL})$ than that in the nonobese group $(78.4 \pm 1.7$ $\mathrm{mg} / \mathrm{dL}$ ), while HDL cholesterol levels were seemed lower in the overweight $(48.3 \pm 0.8 \mathrm{mg} / \mathrm{dL})$ than that in the nonobese group $(53.0 \pm 0.4 \mathrm{mg} / \mathrm{dL})$.

Average TSH levels were $3.1 \pm 0.2 \mu \mathrm{IU} / \mathrm{mL}$ in the overweight and $2.7 \pm 0.1 \mu \mathrm{IU} / \mathrm{mL}$ in the nonobese group. Average fT 4 levels were $1.2 \pm 0.0 \mathrm{ng} / \mathrm{dL}$ in the overweight and $1.3 \pm 0.0 \mathrm{ng} / \mathrm{dL}$ in the nonobese group. Among overweight subjects, 49.1\% (107 of 218) had WC beyond the 90th percentile. Additionally, 8.3\% (18 of 218) of the overweight and 5.8\% (44 of 757) of the nonobese group subjects had TSH levels $>5.5 \mu \mathrm{IU} / \mathrm{mL}$.

\section{Distribution of thyroid function in the study population}

The prevalence of subclinical hypothyroidism (SH) was $6.6 \%$ (67 of 1,021). The prevalence of TPO Ab in patients with SH was $0.3 \%$ ( 3 of 1,021). Subjects with SH consisted of 48 normal weight and 19 obese subjects. The prevalence of total subclinical hyperthyroidism and overt hyperthyroidism was $0.3 \%$ ( 3 of $1,021)$ and $0.8 \%$ ( 8 of 1,021), respectively. The prevalence of $\mathrm{TPO} \mathrm{Ab}$ in patients with overt hyperthyroidism was $0.3 \%$ ( 3 of $1,021)$.

\section{Association between obesity indexes and thyroid function}

We assessed the relationship between TSH level and BMI and WC after dividing the group into 2 according to the TSH level (Table 2). Of the subjects, $11.6 \%$ (113 of 974) were included in the abdominal obesity group, and $22.4 \%$ (218 of 975) were included in the overweight based on BMI. Further, 10.6\% (12 of 113) of abdominal obesity group subjects (WC $\geq 90$ th percentile) had TSH levels $>5.5 \mu \mathrm{IU} / \mathrm{mL}$. There was a positive correlation between abdominal obesity and TSH levels $(P=0.026)$, but no significant correlation was observed between overweight and TSH levels $(P=0.081)$.

\section{Association of obesity and metabolic syndrome-related factors with TSH levels}

We assessed the association between TSH levels and metabolic syndrome-related factors, overweight, and WC (Table 3A, B). Because a distribution of TSH values was skewed, we transformed the data into a log-scale, adjusted for age and gender. There was a significant association between $\log (\mathrm{TSH})$, WC, and TG levels in the univariable model. Overweight and WC were analyzed separately using multivariable model. In the

\begin{tabular}{|c|c|c|c|c|}
\hline Variable & No. & $\mathrm{TSH}>5.5 \mu \mathrm{lU} / \mathrm{mL}$ & $\mathrm{TSH} \leq 5.5 \mu \mathrm{lU} / \mathrm{mL}$ & $X^{2}(P$-value $)$ \\
\hline $\mathrm{BMI}^{*}$ & & & & $4.560(0.081)$ \\
\hline Nonobese & 757 & $44(5.5)$ & $713(94.5)$ & \\
\hline Overweight & 218 & $18(9.5)$ & $200(90.5)$ & \\
\hline$W C^{\dagger}$ & & & & $7.621(0.026)$ \\
\hline Normal & 861 & $49(5.5)$ & $812(94.5)$ & \\
\hline Obese & 113 & $12(10.6)$ & $101(87.9)$ & \\
\hline
\end{tabular}

BMI, body mass index; WC, waist circumference; TSH, thyroid stimulating hormone.

Defined using 2007 Korea growth chart. Calculated by complex samples crosstabs.

"Nonobese (BMI<85th percentile), overweight (BMI $\geq 85$ th percentile). ${ }^{\dagger}$ Normal (<90th percentile), obese ( $\geq 90$ th percentile). 
multivariable model that analyzed $\log (\mathrm{TSH})$ and overweight together, overweight were not significantly associated with TSH levels whereas HDL cholesterol and TG levels showed a significant association with TSH levels. In the multivariable model that analyzed lnTSH and WC, WC, HDL cholesterol levels, and TG levels were all significantly associated. $\log (\mathrm{TSH})$ was higher in the $\mathrm{WC} \geq 90$ th percentile group than that in the WC $<90$ th percentile group by 0.177 .

\section{Association of obesity and metabolic syndrome-related factors with $\mathrm{fT} 4$ levels}

We assessed the association between obesity and metabolic syndrome-related factors including fT4 levels, overweight, and WC (Table 4A, B). In the univariable model of fT4 levels, overweight and WC were significantly associated. In the multivariable model of fT4 levels and overweight, only overweight were significantly associated. The $\mathrm{BMI} \geq 85$ th percentile group had lower fT4 levels than the $\mathrm{BMI}<85$ th percentile group by 0.057 . In the multivariable model of fT4 levels and WC, WC and TG were significantly associated. The WC $\geq 90$ th percentile group had lower fT4 levels than the $\mathrm{WC}<90$ th percentile group by 0.046 .

Table 3A. Association between obesity and metabolic syndrome-related factors with thyroid stimulating hormone

\begin{tabular}{|c|c|c|c|c|c|c|}
\hline \multirow{2}{*}{ Variables } & \multicolumn{3}{|c|}{ Simple } & \multicolumn{3}{|c|}{ Multiple } \\
\hline & $\beta$ & SE & $P$-value & $\beta$ & SE & $P$-value \\
\hline Overweight & 0.104 & 0.058 & 0.075 & 0.081 & 0.059 & 0.174 \\
\hline Systolic blood pressure & 0.005 & 0.003 & 0.068 & 0.003 & 0.003 & 0.246 \\
\hline Diastolic blood pressure & 0.004 & 0.004 & 0.279 & - & - & - \\
\hline Fasting glucose & 0.002 & 0.002 & 0.362 & - & - & - \\
\hline $\mathrm{HbA}_{1 \mathrm{c}}$ & 0.034 & 0.065 & 0.603 & - & - & - \\
\hline HDL cholesterol & 0.003 & 0.002 & 0.181 & 0.006 & 0.003 & 0.013 \\
\hline Triglyceride & 0.001 & 0.000 & 0.001 & 0.002 & 0.000 & 0.000 \\
\hline
\end{tabular}

Adjusted for age, sex.

Calculated by complex samples general linear model.

$\mathrm{SE}$, standard error; $\mathrm{HbA}_{1 c}$ glycated hemoglobin; HDL cholesterol, high-density lipoprotein cholesterol.

Table 3B. Association between abdominal obesity and metabolic syndrome-related factors with thyroid stimulating hormone

\begin{tabular}{|c|c|c|c|c|c|c|}
\hline \multirow{2}{*}{ Variable } & \multicolumn{3}{|c|}{ Simple } & \multicolumn{3}{|c|}{ Multiple } \\
\hline & $\beta$ & SE & P-value & $\beta$ & SE & P-value \\
\hline WC & 0.201 & 0.074 & 0.007 & 0.177 & 0.077 & 0.023 \\
\hline Systolic blood pressure & 0.005 & 0.003 & 0.068 & 0.003 & 0.003 & 0.306 \\
\hline Diastolic blood pressure & 0.004 & 0.004 & 0.279 & - & - & - \\
\hline Fasting glucose & 0.002 & 0.002 & 0.362 & - & - & - \\
\hline $\mathrm{HbA}_{1 c}$ & 0.034 & 0.065 & 0.603 & - & - & - \\
\hline HDL cholesterol & 0.003 & 0.002 & 0.181 & 0.007 & 0.003 & 0.011 \\
\hline Triglyceride & 0.001 & 0.000 & 0.001 & 0.002 & 0.000 & 0.001 \\
\hline
\end{tabular}

Adjusted for age, sex.

Calculated by complex samples general linear model.

WC, waist circumference; SE, standard error; $\mathrm{HbA}_{1,}$ glycated hemoglobin; HDL cholesterol, high-density lipoprotein cholesterol.

Table 4A. Association between obesity metabolic syndrome-related factors with free thyroxine

\begin{tabular}{|c|c|c|c|c|c|c|}
\hline \multirow{2}{*}{ Variable } & \multicolumn{3}{|c|}{ Simple } & \multicolumn{3}{|c|}{ Multiple } \\
\hline & $\beta$ & SE & $P$-value & $\beta$ & SE & $P$-value \\
\hline Overweight & -0.050 & 0.015 & 0.001 & -0.057 & 0.016 & 0.000 \\
\hline Systolic blood pressure & 0.001 & 0.001 & 0.117 & 0.001 & 0.001 & 0.156 \\
\hline Diastolic blood pressure & 0.002 & 0.001 & 0.172 & 0.001 & 0.001 & 0.448 \\
\hline Fasting glucose & 0.002 & 0.001 & 0.077 & 0.001 & 0.001 & 0.098 \\
\hline $\mathrm{HbA}_{1 \mathrm{c}}$ & 0.015 & 0.033 & 0.660 & - & - & - \\
\hline HDL cholesterol & 0.000 & 0.001 & 0.771 & - & - & - \\
\hline Triglyceride & 0.000 & 0.000 & 0.052 & 0.000 & 0.000 & 0.067 \\
\hline
\end{tabular}

Adjusted for age, sex.

Calculated by complex samples general linear model.

$\mathrm{SE}$, standard error; $\mathrm{HbA}_{1 c}$ glycated hemoglobin; HDL cholesterol, high-density lipoprotein cholesterol. 
Table 4B. Association between abdominal obesity metabolic syndrome-related factors with free thyroxine

\begin{tabular}{|c|c|c|c|c|c|c|}
\hline \multirow{2}{*}{ Variable } & \multicolumn{3}{|c|}{ Simple } & \multicolumn{3}{|c|}{ Multiple } \\
\hline & $\beta$ & SE & $P$-value & $\beta$ & SE & $P$-value \\
\hline$\overline{W C}$ & -0.042 & 0.018 & 0.023 & -0.046 & 0.018 & 0.014 \\
\hline Systolic blood pressure & 0.001 & 0.001 & 0.117 & 0.001 & 0.001 & 0.329 \\
\hline Diastolic blood pressure & 0.002 & 0.001 & 0.172 & 0.001 & 0.001 & 0.375 \\
\hline Fasting glucose & 0.002 & 0.001 & 0.077 & 0.001 & 0.001 & 0.105 \\
\hline $\mathrm{HbA}_{1 c}$ & 0.015 & 0.033 & 0.660 & - & - & - \\
\hline HDL cholesterol & 0.000 & 0.001 & 0.771 & - & - & - \\
\hline Triglyceride & 0.000 & 0.000 & 0.052 & 0.000 & 0.000 & 0.039 \\
\hline
\end{tabular}

Adjusted for age, sex.

Calculated by complex samples general linear model.

WC, waist circumference; $\mathrm{SE}$, standard error; $\mathrm{HbA}_{1,}$ glycated hemoglobin; $\mathrm{HDL}$ cholesterol, high-density lipoprotein cholesterol.

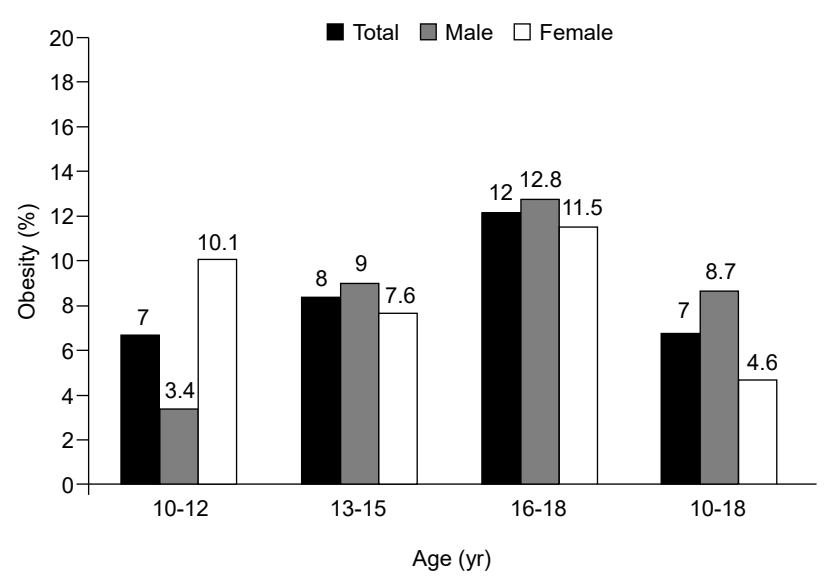

Fig. 1. Prevalence of the subjects with obesity* who 10-18 years old children in the Korea National Health and Nutrition Examination Survey IV (2013-2015). *Using 2007 Korean national growth chart, obesity defined body mass index $\geq$ 95th percentile

\section{Discussion}

Metabolic syndrome in obese children is positively correlated with the level of obesity. ${ }^{15)}$ Among Korean children, the prevalence of obesity has been higher in males than in females since 1997. The prevalence of metabolic syndrome as well has been higher in males than in females since 2001. ${ }^{6,16)}$ In this study, the prevalence of childhood obesity (BMI $\geq 95$ th percentile) was $8.7 \%$ ( 45 of 516$)$ in males and $4.6 \%$ (21 of 459$)$ in females (Fig. 1). The prevalence of overweight phenotype (BMI $\geq 85$ th percentile) in children was $22.7 \%$ (104 of 459 ) in girls and $22.1 \%$ (114 of 516) in boys, and the prevalence of abdominal obesity was $12.7 \%$ (58 of 458) in girls and 10.7\% (55 of 516) in boys.

Many recent cross-sectional studies reported on the association between thyroid hormones and obesity. In most studies, serum TSH levels were higher in obese children than in normal weight children, ${ }^{3-8,17)}$ and fT4 levels were similar between the two groups. ${ }^{3-5,17)}$ In our study, there was no significant relationship between the TSH level and the obesity group, and the TSH level and the overweight group $(P=0.075, P=0.218)$. Serum TSH and fT3 levels were positively correlated with BMI $z$-score. ${ }^{5,6)}$ It is estimated that the TSH concentrations may be higher in the obesity group than in the overweight group. A few longitudinal studies reported TSH levels to be higher in obese children than that in normal weight children and these levels normalized after weight loss. Reinehr et al. ${ }^{4)}$ compared obese children and children with anorexia nervosa (AN). Baseline TSH levels were high in obese children and low in children with AN. While serum TSH levels in obese children decreased with weight loss, TSH levels in children with AN increased with weight gain.

TSH levels reversibly change according to changes in weight. High levels of TSH in obese children are thought to be owing to obesity, and T3 levels are often already elevated. Therefore, initial treatment of obese children with SH should include lifestyle intervention rather than thyroid hormone replacement therapy. ${ }^{3,5,6)}$

Although the mechanisms of changes in thyroid hormone levels in obese children are still unclear, there are a few hypotheses stating that leptin is likely responsible for controlling hypothalamic production of TSH. Leptin, a hormone secreted by adipose tissues, is involved in the control of food intake, regulation of energy expenditure, and homeostasis of body weight. ${ }^{18)}$ Leptin levels are higher in obese children than in normal weight children. ${ }^{4)}$ It is supposed, since leptin is involved in the hypothalamic production of TSH, serum TSH and leptin levels in obese females are estimated to decrease simultaneously after weight loss. ${ }^{19)}$ Also, there is a hypothesis that the increase of the TSH and T3 levels in obesity is an adaptation process. Resting energy expenditure is positively correlated with serum fT3 levels. It is an adaptation process to increase calorie consumption in order to prevent extra weight gain in obesity children. On the other hand, when losing weight, the fT3 levels decrease. This makes it difficult to add additional weight loss. But, the exact mechanism is not fully understood. ${ }^{6)}$

Subjects with hypothyroidism have higher prevalences of dyslipidemia, hypertension, atherosclerosis, and coronary heart disease than individuals with euthyroidism, but the association is still unclear. The prevalence of metabolic syndrome was higher than the low TSH group in the high TSH group. ${ }^{20,21)}$ Mamtani et al. ${ }^{22)}$ reported that among metabolic syndromerelated factors, WC, BMI, and abdominal obesity were 
significantly associated with thyroid function. In this study, we showed that abdominal obesity represented by WC was more related to serum TSH levels than obesity represented by BMI $z$-scores. Deviating from previous studies, ${ }^{3-8)}$ on the result of this study that there was no clear association observed between BMI and TSH levels is likely due to the smaller proportion of obese children in this sample. Among the entire study subjects $(\mathrm{n}=975)$, only 218 and 51 children were overweight and obese, respectively.

Shalitin et al. ${ }^{17)}$ assessed anthropometric and laboratory variables after putting the obese children into 12 -week weight reduction programs. In the group that had reduced BMI $z$-scores after the intervention, analysis of anthropometric and laboratory variables showed an association between TSH levels and WC, but not between TSH levels and BMI $z$-scores, compared to the group that did not exhibit reduced BMI $z$-scores. There are several studies that assess the association between TSH levels and obesity. To date, the relationship has not been clearly defined.

There are 3 major limitations of this study. First, the crosssectional characteristic of this study allows us to assess the association between thyroid hormones and abdominal obesity, but the causal relationship could not be identified. Second, Thyroid hormone related data included only TPO Ab, TSH, and fT4. There was a limit to data presentation compared to previous studies. Third, because we only had partial data on fasting insulin levels, which are associated with the metabolic syndrome, we could not assess the association between insulin resistance and TSH levels.

Despite these limitations, unlike previous studies from Korea, this study included a large survey of Korean children with normal weight. The KNHANES collects representative data for the nation, and therefore we could predict the prevalence of obesity and SH in Korean children. Therefore, this is the first study in Korea to assess the relationship between abdominal obesity and TSH levels in children. In this study, the association was clearer between TSH levels and abdominal obesity than between TSH levels and obesity. In addition, serum TSH levels were correlated with metabolic syndrome-related factors such as HDL cholesterol and TG levels. In conclusion, children with abdominal obesity tend to reveal thyroid dysfunction. Therefore, when children are diagnosed with abdominal obesity, they may consider thyroid function test as well as the metabolic syndrome-related factors.

Further studies are needed to clarify the mechanisms and assess the association between lipid and TSH levels in children.

\section{Conflict of interest}

No potential conflict of interest relevant to this article was reported.

\section{Acknowledgments}

The authors thank the participants in the 2013-2015 KNHANES

\section{References}

1. Nathan BM, Moran A. Metabolic complications of obesity in childhood and adolescence: more than just diabetes. Curr Opin Endocrinol Diabetes Obes 2008;15:21-9.

2. Kokkoris P, Pi-Sunyer FX. Obesity and endocrine disease. Endocrinol Metab Clin North Am 2003;32:895-914.

3. Reinehr T, de Sousa G, Andler W. Hyperthyrotropinemia in obese children is reversible after weight loss and is not related to lipids. J Clin Endocrinol Metab 2006;91:3088-91.

4. Reinehr T, Isa A, de Sousa G, Dieffenbach R, Andler W. Thyroid hormones and their relation to weight status. Horm Res 2008;70:51-7.

5. Marras V, Casini MR, Pilia S, Carta D, Civolani P, Porcu M, et al. Thyroid function in obese children and adolescents. Horm Res Paediatr 2010;73:193-7.

6. Grandone A, Santoro N, Coppola F, Calabrò P, Perrone L, Del Giudice EM. Thyroid function derangement and childhood obesity: an Italian experience. BMC Endocr Disord 2010;10:8. https://doi.org/10.1186/1472-6823-10-8.

7. Wolters B, Lass N, Reinehr T. TSH and free triiodothyronine concentrations are associated with weight loss in a lifestyle intervention and weight regain afterwards in obese children. Eur J Endocrinol 2013;168:323-9.

8. Knudsen N, Laurberg P, Rasmussen LB, Bülow I, Perrild $\mathrm{H}$, Ovesen L, et al. Small differences in thyroid function may be important for body mass index and the occurrence of obesity in the population. J Clin Endocrinol Metab 2005;90:4019-24.

9. Ministry for Health, Welfare and Family Affairs. The Sixth Korea National Health and Nutrition Examination Survey (KNHANES VI) [Internet]. Seoul (Korea): Ministry for Health, Welfare and Family Affairs; 2017 [cited 2017 Jan 9]. Available from: http://knhanes.cdc.go.kr.

10. Barlow SE; Expert Committee. Expert committee recommendations regarding the prevention, assessment, and treatment of child and adolescent overweight and obesity: summary report. Pediatrics 2007;120 Suppl 4:S164-92.

11. Cole TJ. The LMS method for constructing normalized growth standards. Eur J Clin Nutr 1990;44:45-60.

12. Moon JS, Lee SY, Nam CM, Choi JM, Choe BK, Seo JW, et al. 2007 Korean National Growth Charts: review of developmental process and an outlook. Korean J Pediatr 2008;51:1-25.

13. International Diabetes Federation. The IDF consensus worldwide definition of the metabolic syndrome [Internet]. Brussels (Belgium): International Diabetes Federation; 2005 [cited 2018 Sep 18]. Available from: Available from: https://www.idf.org/ e-library/consensus-statements/60-idfconsensus-worldwide- 
definitionof-the-metabolic-syndrome.html.

14. Alberti KG, Zimmet P, Shaw J; IDF Epidemiology Task Force Consensus Group. The metabolic syndrome--a new worldwide definition. Lancet 2005;366:1059-62.

15. Weiss R, Dziura J, Burgert TS, Tamborlane WV, Taksali SE, Yeckel CW, et al. Obesity and the metabolic syndrome in children and adolescents. N Engl J Med 2004;350:2362-74.

16. Ha KH, Kim DJ. Epidemiology of childhood obesity in Korea. Endocrinol Metab (Seoul) 2016;31:510-8.

17. Shalitin S, Yackobovitch-Gavan M, Phillip M. Prevalence of thyroid dysfunction in obese children and adolescents before and after weight reduction and its relation to other metabolic parameters. Horm Res 2009;71:155-61.

18. Friedman JM, Halaas JL. Leptin and the regulation of body weight in mammals. Nature 1998;395:763-70.

19. Kok P, Roelfsema F, Langendonk JG, Frölich M, Burggraaf J, Meinders AE, et al. High circulating thyrotropin levels in obese women are reduced after body weight loss induced by caloric restriction. J Clin Endocrinol Metab 2005;90:4659-63.

20. Oh JY, Sung YA, Lee HJ. Elevated thyroid stimulating hormone levels are associated with metabolic syndrome in euthyroid young women. Korean J Intern Med 2013;28:180-6.

21. Lee YK, Kim JE, Oh HJ, Park KS, Kim SK, Park SW, et al. Serum TSH level in healthy Koreans and the association of TSH with serum lipid concentration and metabolic syndrome. Korean J Intern Med 2011;26:432-9.

22. Mamtani M, Kulkarni H, Dyer TD, Almasy L, Mahaney $\mathrm{MC}$, Duggirala R, et al. Increased waist circumference is independently associated with hypothyroidism in Mexican Americans: replicative evidence from two large, population-based studies. BMC Endocr Disord 2014;14:46. 